neuronal transport and causes neuronal degeneration and death.

The section on prevention focuses on the usual suspects: stress, diet, exercise, brain training, and sleep. A gallop through the evidence leads to the predictable conclusion that, though none of these options offers any dramatic promise, in the author's words:

'... these lifestyle measures are good for us anyway, [so] play it safe ... follow a Mediterranean diet. Exercise. Avoid stress. Stimulate your mind. Sleep. You've got nothing to lose and everything to gain.

The remaining chapters take us all over the globe, through a number of cutting-edge research projects in neurobiochemistry, and some tantalising possibilities. Plasma infusions can improve memory, perhaps through proteins that stimulate neurogenesis in the hippocampus. Prions, virus-like proteins that include the entities responsible for CJD and kuru, seem also to have some protective function. The observation that cancer susceptibility and Alzheimer's are negatively correlated has led to speculation about the possibility of using certain chemotherapeutic agents early in the disease. And the fact that the low prevalence of Alzheimer's in Iceland is due to a single protective mutation at the same site as the mutation that causes early-onset Alzheimer's offers some hope for drug treatment aimed at amyloid production and breakdown. A village in India provides a case study for the possible protective effects of turmeric, while a village in Colombia by contrast has a concentration of another familial form of the disease characterised by a distinctive form of 'cotton wool' plaques.

Jebelli exudes a sense of optimism, and believes that there will be an effective treatment for the disease within his lifetime. A lot of hope is pinned on gene modification, and in particular on the gene-editing tool known as CRISPR.

The author never loses sight of the human stories: those of the scientists dedicating their lives to defeating this horrible disease, but, more importantly, those of its sufferers and their families. His humanity complements his hopefulness, and his readers should be grateful for both.

\section{Dougal Jeffries}

Brillwater House, Constantine, Cornwall.

dougal6agmail.com

DOI: https://doi.org/10.3399/bjgp17X693785

\section{Migration, Illness \& Healthcare Jenny Altschuler}

Palgrave Macmillan, 2016, PB, 280pp, E24.99, 978-1137378507

Migration,
Illness \&,
Healthcare
Jenny
Altschuler

\section{A JOURNEY THROUGH MIGRATION AND ITS IMPACT ON HEALTH}

Migrant health has never been more relevant. In 2016 an unprecedented 65.6 million people were forcibly displaced worldwide. ${ }^{1}$ Providing equitable care presents enormous challenges, from the politics of healthcare policy to the nuances of cross-cultural consultations in daily practice.

Altschuler's new book is a timely and fascinating exploration of these issues and much more. She does not shy away from writing about the diversity of migrant experiences: from professional economic migrants choosing to work for the NHS, to how survivors of torture may struggle to trust clinicians in positions of power.

Working as an inner-city GP I recognise many of the patients and the situations. In one chapter Altschuler describes cultural dissonance between first- and secondgeneration migrants, and how this impacts on health and wellbeing. In another chapter the differences in the cultural constructions of illness and death are examined. She reminds us that Western concepts often fail to understand the 'spiritual' dimension of wellbeing. An example given is a study showing that Hindu women undergoing treatment for cervical cancer had a better psychological recovery if they believed the cancer was caused by God's will rather than linking it to their own bodily weakness or mental stress.

As healthcare professionals we are challenged to reflect on our own cultural beliefs and values, and on how these influence our ability to communicate with patients and provide sensitive care. Altschuler tackles politically thorny issues including restrictive healthcare policy and the barriers faced by vulnerable patient groups trying to access care.
The real appeal of this book lies in the narrative, into which Altschuler artfully weaves case studies, contemporary research, and her own personal experiences of migration. She is an adept storyteller and writer, and her expertise as a family psychotherapist is evident throughout, providing a compelling and accessible analysis of the topic.

This book is an invaluable resource for GPs, healthcare professionals, and readers interested in healthcare policy or the wider issues related to migration and health. It not only gives practical recommendations, but also raises questions about how as individuals and as a society we can provide more equitable health care.

\section{Hannah Fox,}

Locum, London.

DOI: https://doi.org/10.3399/bjgp17X693797

\section{REFERENCE}

1. UNHCR. The UN Refugee Agency. 20 people are newly displaced every minute of the day. http://www.unhcr.org/globaltrends2016/ laccessed 24 Oct 2017). 